Journal of Computer Science 7 (4): 466-470, 2011

ISSN 1549-3636

(C) 2011 Science Publications

\title{
Stress Prediction in the Dynamic Compression Plate with Changing the Configuration of the Screw Fixation
}

\author{
Boonthum Wongchai \\ Department of Mechanical Engineering, Faculty of Engineering at Si Racha, \\ Kasetsart University, 199 M.6, Tungsukhla, Si Racha, Chonburi, 20230, Thailand
}

\begin{abstract}
Problem statement: Human femur fracture is one of the most frequent type of bone fractures. One of the widely used methods in an internal fixation is an application of the Dynamic Compression Plate (DCP). The configuration of the screw fixation plays a major role of the DCP stress. Approach: This research is proposed to investigate the stress distribution in the 14-hole DCP by using Finite Element Analysis (FEA), eight configurations of the screw fixation with the body weight of 50 and $70 \mathrm{~kg}$. The maximum von Mises stress on the DCP in each configuration is used to find the best of the screw fixations. The equations of the maximum von Mises stress are formulated by the regression analysis. Results: The experimental results show that the relation of the maximum von Mises stress and the number of screws are the linear equation. Conclusion: The maximum von Mises stress from FEA could be predicted by using the linear equation.
\end{abstract}

Key words: Stress prediction, screw fixation, dynamic compression plate, femur fracture

\section{INTRODUCTION}

Femur fracture is the most significant osteoporotic fracture. The Dynamic Compression Plate (DCP) is one of the most commonly used implants for internal fixation. The body load will be transmitted from the screw through the DCP. The DCP fails when the maximum von Mises stress is greater than the yield strength of DCP material. The internal fixation devices are usually made of non-corrosive metal such as stainless steel and titanium alloys. Nowadays the fiber reinforce composite materials have been investigated for the new choices better than stainless steel and titanium alloys (Kim et al., 2010). The cyclic body load is an important force during walking varies from 0 to full body load. It may cause the plate is damaged by fatigue mode (Kanchanomai et al., 2008; Ahmad et al., 2007).

When the fracture occurs at the middle part of the femur, the physician will cut the fracture and form a gap of 1 to $10 \mathrm{~mm}$. Subsequently, the fractured femur is bridged by using an internal fixation plate. The interfragmentary strain (IFS) is defined as the ratio of the fracture gab displacement after the body load applied and the original fracture gab. The best IFS range between $2 \%$ to $10 \%$ (Perren, 1979). The fracture gab about 1 to $10 \mathrm{~mm}$ usually used in the research (Kim et al., 2010; Kanchanomai et al., 2008; Ahmad et al., 2007; Stoffel et al., 2003; Saffar et al., 2009; Sadi et al., 2010).

There are many causes affecting the DCP stress, including the DCP length, number of holes, the screw preload, the fracture gab, the configuration of the screw fixation and etc. The configuration of the screw fixation plays a major role of the DCP stress.

\section{MATERIALS AND METHODS}

Finite Element Analysis (FEA): The tree-dimension finite element model is modeled from the second generation femur of Pacific Research Lab (Viececonti et al., 2003). Each screw configuration is modeled in SolidWorks 2004 software and transformed into finite element models by using ABAQUS 6.4 software with the four-node tetrahedral elements.

The DCP and the screw material are 316L stainless steel, with Young's modulus of $193 \mathrm{MPa}$ and a Poission's Ratio of 0.3. The femur was composed of the cortical bone and the cancellous bone. The cortical bone is modeled with Young's modulus of $15 \mathrm{GPa}$ and Poission's Ratio of 0.33, while the cancellous bone is modeled with Young's modulus of $1.1 \mathrm{GPa}$ and Poission's Ratio of 0.33 (Lengsfeld et al., 1998).

Force Analysis: The ilium shown in Fig.1 is loaded by a half of body load $\left(\mathrm{F}_{\mathrm{w}}\right)$, the abduction force $\left(\mathrm{F}_{\mathrm{a}}\right)$ and the hip force $\left(F_{h}\right)$. The force vector polygon is represented in Fig. 2.

The related equations including those mentioned forces are formulated by using the Newton's first law. The summing of the force vectors will be equal to zero.

$\overrightarrow{\mathrm{F}}_{\mathrm{h}}+\overrightarrow{\mathrm{F}}_{\mathrm{a}}+\overrightarrow{\mathrm{F}}_{\mathrm{w}}=0$ 


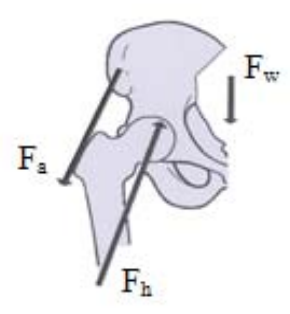

Fig. 1: The body load and the forces on the ilium (Hall 2007)

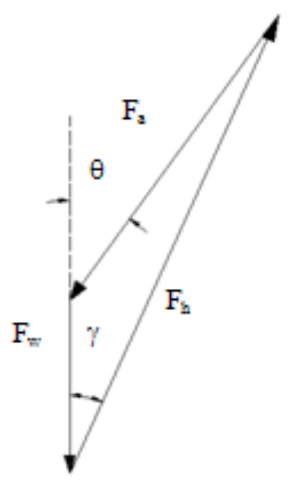

Fig. 2: The force vector polygon

Table 1: Force components in $\mathrm{x}$ and y directions
\begin{tabular}{lllll}
\hline Body weight $(\mathrm{kg})$ & $\mathrm{F}_{\mathrm{ax}}(\mathrm{N})$ & $\mathrm{F}_{\text {ay }(\mathrm{N})}$ & $\mathrm{F}_{\mathrm{hx}}(\mathrm{N})$ & $\mathrm{F}_{\mathrm{hy}}(\mathrm{N})$ \\
\hline 50 & 295.56 & 354.24 & -342.36 & -592.98 \\
70 & 413.79 & 493.13 & -479.30 & -830.17 \\
\hline
\end{tabular}

Table 2: The screw configurations on each side

\begin{tabular}{|c|c|c|}
\hline Model & Fixed at hole-number & Number of screws \\
\hline 1 & 123456 & 6 \\
\hline 2 & 13456 & 5 \\
\hline 3 & 456 & 4 \\
\hline 4 & 56 & 3 \\
\hline 5 & 1 & 2 \\
\hline 6 & 12 & 3 \\
\hline 7 & 123 & 4 \\
\hline 8 & 12346 & 5 \\
\hline
\end{tabular}

Table 3: The groups of screw configuration

\begin{tabular}{lll}
\hline Group & Model & Number of screws \\
\hline 1 & 54321 & 23456 \\
2 & 56781 & 23456 \\
\hline
\end{tabular}

From Fig. 2 the values of angle $\theta$ and $\gamma$ were $29^{\circ}$ and $19^{\circ}$ according to Waide research (Waide et al., 2003). The y axis is aligned along the axial direction of the femur as show in Fig. 3. The forces in $x$ and $y$ directions are

$$
\begin{aligned}
& \mathrm{F}_{\mathrm{ax}}=\mathrm{F}_{\mathrm{a}} \sin 40^{\circ} \\
& \mathrm{F}_{\mathrm{ay}}=\mathrm{F}_{\mathrm{a}} \cos 40^{\circ}
\end{aligned}
$$

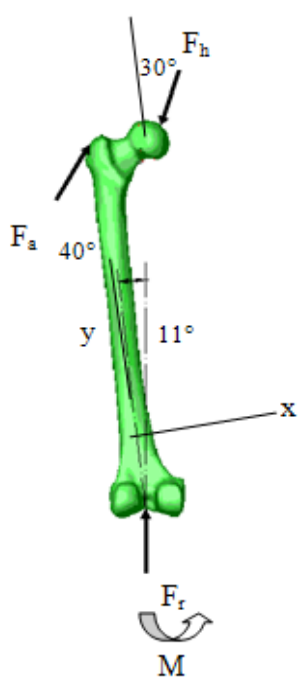

Fig. 3: The free body diagram of the femur

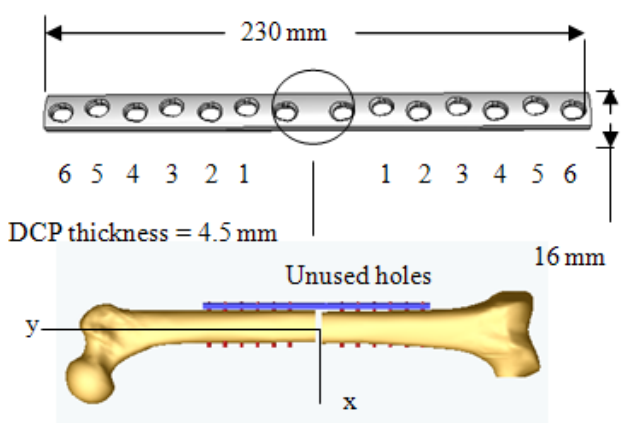

Fig. 4: The hole-number of the DCP

$\mathrm{F}_{\mathrm{hx}}=-\mathrm{F}_{\mathrm{h}} \sin 30^{\circ}$

$\mathrm{F}_{\mathrm{hy}}=-\mathrm{F}_{\mathrm{h}} \cos 30^{\circ}$

From equations (2) to (5) the values of $\mathrm{F}_{\mathrm{ax}}, \mathrm{F}_{\mathrm{ay}}, \mathrm{F}_{\mathrm{hx}}$ and $\mathrm{F}_{\text {hy }}$ as shown in Table 1, we obtain the body weights of $50 \mathrm{~kg}$ and $70 \mathrm{~kg}$.

The forces acting on the femur as shown in Fig. 3 have the opposite directions to their reaction forces in Fig. 1 . The angle between y axis and the vertical axis is $11^{\circ}$ (Cristofolini et al., 1996; Hall, 2007; Waide et al., 2003) . The reaction force $\left(F_{r}\right)$ and the reaction moment (M) occur at the femur and the tibia joint. At this joint, the fixed condition is defined in finite element model.

The screw configurations: The $10-\mathrm{mm}$ fracture gab was bridged by the 14-hole DCP as shown in Fig. 4. The femur and the DCP are fixed by the $4.5-\mathrm{mm}$ 467 
diameter screws. Two screws were fixed at $1^{\text {st }}$ and $6^{\text {th }}$ holes on both sides. The other holes are fixed with additional screws. Two holes at the middle are left without any screws.

The eight configurations of screw fixation are shown in Table 2. The contact conditions are applied on the finite element model, the glue condition between screw and plate, the glue condition between screw and femur and the touching condition between plate and femur.

Two groups of screw configuration are conducted by using the direction of the screw fixation as shown in Table 3. The number of screws varies from 2 to 6 .

\section{RESULTS}

The results from FEA are shown in Table 4. We found that the maximum von Mises stress on the DCP is occurred in the DCP hole near the fracture gab (unused hole) for all cases as shown in Fig. 5.

From the groups of the screw configuration in Table 3 and the maximum von Mises stress in Table 4, we represented the maximum von Mises stress versus the number of the screws in Fig. 6.

Table 4: The maximum von Mises stress ( $\sigma_{\text {von }}$ ) on the DCP

\begin{tabular}{lll}
\hline & Body weight $50 \mathrm{~kg}$ & Body weight 70 kg \\
Model & $\sigma_{\text {von }}(\mathrm{MPa})$ & $\sigma_{\text {von }}(\mathrm{MPa})$ \\
\hline 1 & 661 & 776 \\
2 & 943 & 1547 \\
3 & 947 & 1459 \\
4 & 998 & 1692 \\
5 & 1203 & 1991 \\
6 & 969 & 1554 \\
7 & 1026 & 1507 \\
8 & 1033 & 1485 \\
\hline
\end{tabular}

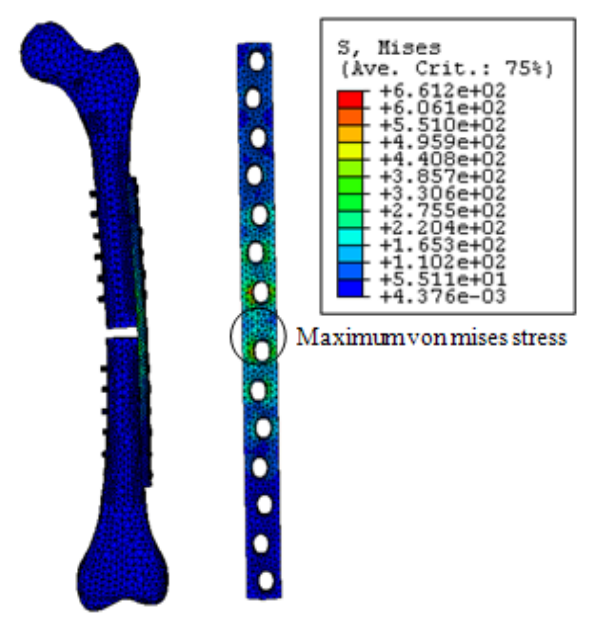

Fig. 5: The von Mises stress on the DCP, body weight $50 \mathrm{~kg}$, model 1
From the regression analysis, we found that the relation of the maximum von Mises stress and the number of screws are the linear equation as follow:

$\sigma_{\text {von }}=\mathrm{a}+\mathrm{bN}$

When $\mathrm{a}$ and $\mathrm{b}$ are constants, while $\mathrm{N}$ is number of screws.

The $R$ square $\left(R^{2}\right)$, the statistical significance $(\alpha)$ and the values of a and $b$, are shown in Table 5 .

From equation (6) and Table 5, we could be constructed the linear equations by using the linear regression analysis as shown in Fig. 7-10.

Table 5: The regression analysis and the parameter estimates

\begin{tabular}{lllll}
\hline Graph & $\mathrm{R}^{2}$ & $\mathrm{a}$ & $\mathrm{a}$ & $\mathrm{b}$ \\
\hline 50 kg group 1 & 0.865 & 0.022 & $1.405 \times 10^{3}$ & -113.8 \\
50 kg group 2 & 0.842 & 0.028 & $1.437 \times 10^{3}$ & -114.7 \\
70 kg group 1 & 0.823 & 0.033 & $2.523 \times 10^{3}$ & -257.5 \\
70 kg group 2 & 0.732 & 0.064 & $2.407 \times 10^{3}$ & -236.1 \\
\hline
\end{tabular}

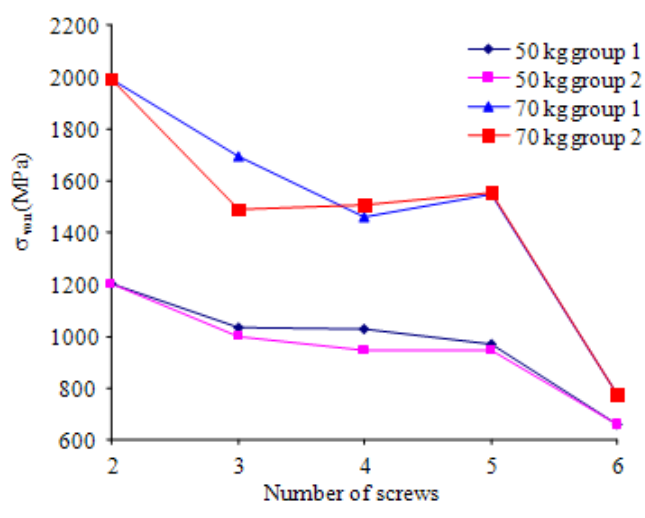

Fig. 6: The maximum von Mises stress versus the number of screws

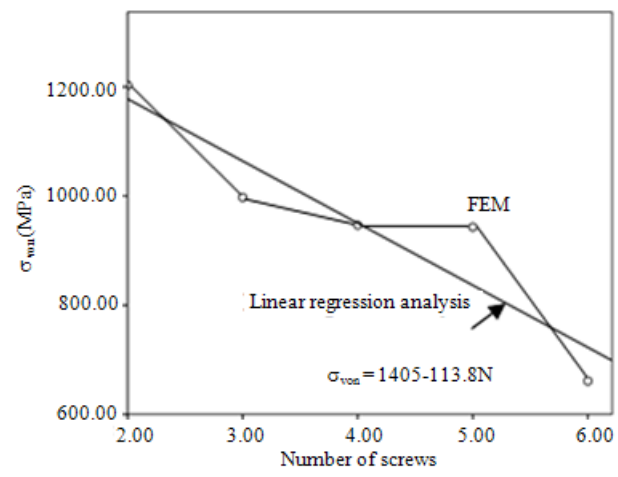

Fig. 7: The linear regression analysis (50 kg group 1) 


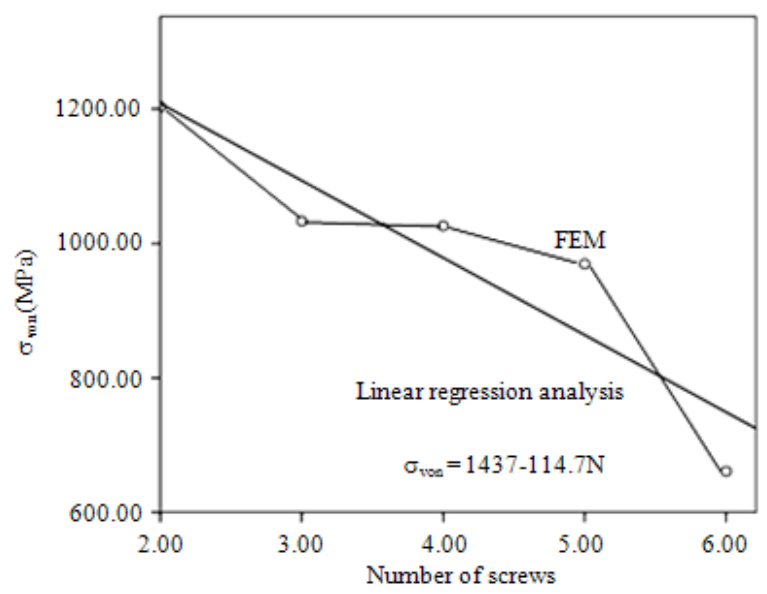

Fig. 8: The linear regression analysis (50 kg group 2)

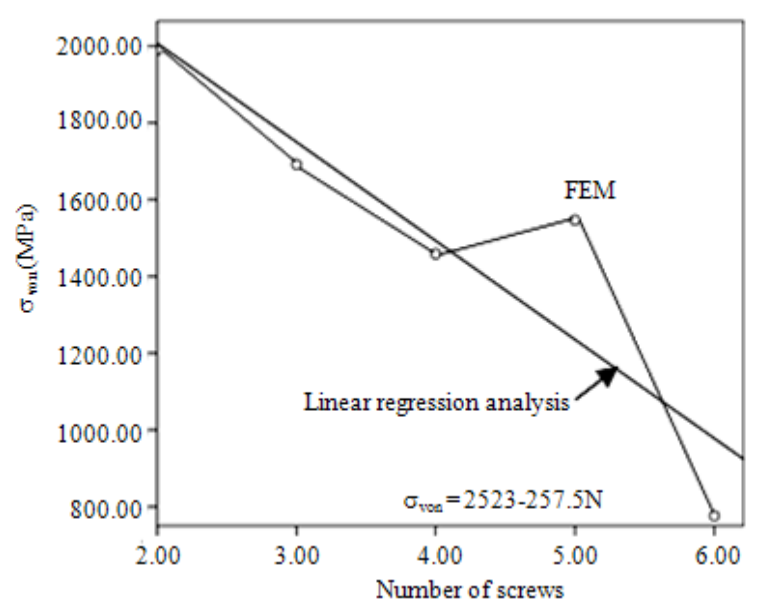

Fig. 9: The linear regression analysis (70 kg group 1)

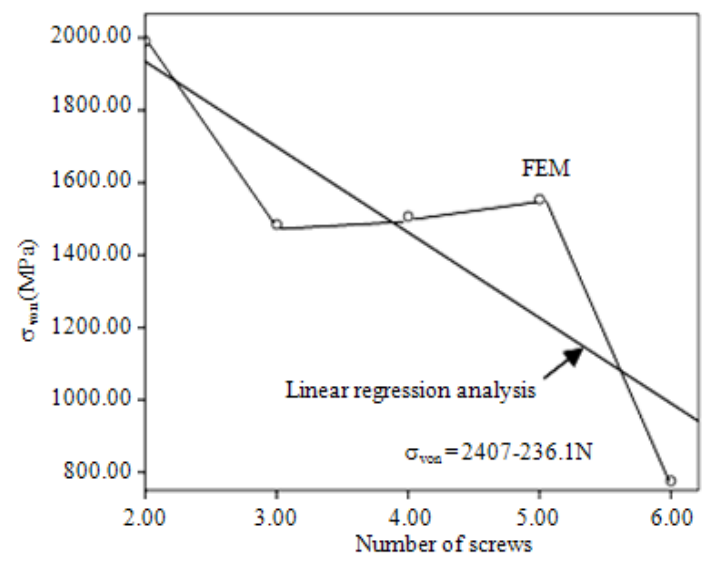

Fig. 10: The linear regression analysis (70 kg group 2)

\section{DISCUSSION}

The results form FEA show that the maximum von Mises stress on the DCP occurs in the unused holes for all cases.

From the graph in Fig. 6, it has been found that the relations between the von Mises stress and the number of screws are the inverse variations. The von Mises stress could be decreased by increasing the number of screws. The best of screw configuration is model 1 with six screws on each side.

From the regression analysis in Table 5 and equation (6), we could predict the maximum von Mises stress by using the linear equation with the statistical significance $\alpha$ less than 0.064 .

\section{CONCLUSION}

The maximum von Mises stress from FEA could be predicted by using the linear equation. We could decrease the maximum von Mises stress on the DCP by adding the number of screw with the groups of screw configuration.

\section{REFERENCES}

Ahmad, M., R. Nanda, A.S. Bajwa, J. Candl-Couto and S. Green et al., 2007. Biomechanical testing of the locking compression plate: When does the distance between bone and implant significantly reduce construct stability? Injury, 38, 358-364. PMID: 17296199

Cristofolini, L., M. Viceconti, A. Cappello and A. Toni. 1996. Mechanical validation of whole bone composite femur models. J. Biomech., 29: 525-535. DOI: 10.1016/0021-9290(95)00084-4

Hall, S.J., 2007. Basic Biomechanics. 5th Edn., McGraw-Hill, New Delhi, ISBN-10: 0071104313, pp: 544.

Kanchanomai, C., V. Phiphobmongkol and P. Muanjn, 2008. Fatigue failure of an orthopedic implant - a locking compression plate. Eng. Failure Anal., 15: 521-530. DOI: 10.1016/j.engfailanal.2007.04.001

Kim, S.H., S.H. Chang and H.J. Jung, 2010. The finite element analysis of a fractured tibia applied by composite bone plates considering contact conditions and time-varying properties of curing tissues, Composite Struc., 92: 2109-2118. DOI: 10.1016/j.compstruct.2009.09.051

Lengsfeld, M., J. Schmitt, P. Alter, J. Kaminsky and R. Leppek, 1998. Comparison of geometry-based and CT voxel-based finite element modelling and experimental validation. Med. Eng. Phy., 20: 515-522. PMID: 9832027 
Perren, SM., 1979. Physical and biological aspects of fracture healing with special reference to internal fixation. Clin. Orthop. Relat. Res., 138: 175-196. PMID: 376198

Sadi, F., A. Veshkini, D. Sharifi and M.N. Masouleh, 2010. Ultrasonography and radiography evaluation of the cartilage graft in repair of experimentally induced radial bone defect in rabbit. Am. J. Anim. Vet. Sci., 5: 40-44. DOI: 10.3844/ ajavsp.2010.40.44

Saffar, K.P., N. JamilPour and S.M. Rajaai, 2009. How does the bone shaft geometry affect its bending properties? Am. J. Applied Sci., 6: 463-470. DOI: 10.3844/ajassp.2009. 463.470
Stoffel, K., U. Dieter, G. Stachowiak, A. Gachter and M.S. Kuster, 2003. Biomechanical Testing of the LCP- how can stability in locked internal fixators be controlled. Injury, 34: 11-19. DOI: 10.1016/j.injury.2003.09.021

Waide, V., L. Critofolimi, J. Stolk, N. Verdonschot and A. Toni, 2003. Experimental investigation of bone remodelling using composite femurs. Clin. Biomech., 18: 523-536. DOI: 10.1016/S02680033(03)00072-X 